\title{
Indícios de conhecimentos musicais nas concepções estilísticas preliminares de pianistas pós-graduandos: um estudo quase-experimental
}

Indications of musical knowledge in the preliminary stylistic conceptions of graduate pianists: a quasi-experimental study

Samuel Henrique da Silva Cianbroni ${ }^{1}$ Universidade Federal do Rio Grande do Sul (UFRGS) shcianbroni@gmail.com

Regina Antunes Teixeira dos Santos ${ }^{2}$ Universidade Federal do Rio Grande do Sul (UFRGS) regina.teixeira@ufrgs.br 


\section{Resumo}

Este artigo tem por objetivo mapear indícios de conhecimentos musicais nas concepções preliminares de estilo demonstradas nas falas de jovens pianistas em nível de pós-graduação, na preparação de três obras impostas de períodos históricos distintos. Um quase-experimento foi realizado com três estudantes de piano cursando mestrado e doutorado em Música, em que os participantes aprenderam obras musicais de diferentes períodos (séc. XVIII, XIX e XX) e compositores (Haydn, Chopin e Bartók) em três sessões de estudo. Entrevistas e registros das obras pelos participantes permitiram coletar concepções para performances. Os resultados demonstraram consenso nas concepções sobre compositores e estilos em que os participantes já tinham experiência prévia de estudo de repertório (Haydn, Chopin), sendo que em Bartók, o consenso foi pequeno. A investigação trouxe evidências de que as referências relacionadas de modos de expressão musical prévios, organização explícita de entendimento (pré-concebido), assim como recepção/percepção na qualidade de intérprete-ouvinte parecem ser indícios consistentes de interconectar conhecimentos estilísticos e avançar perspectivas de conhecimento musical de instrumentistas em formação.

Palavras-chave: Conhecimento Musica. Estilo. Prática Musical. Pianista. Performance.

\section{Abstract}

This article aims to map indications of musical knowledge in the musical preliminary conceptions of style demonstrated in the speeches of young pianists at the graduate level in the preparation of three imposed works from different historical periods. A quasi-experiment was carried out with three piano students at Master and $\mathrm{PhD}$ degrees in Music, in which the participants learned musical works from different periods (18th, 19th and 20th centuries) and composers (Haydn, Chopin and Bartók) in three practice sessions. Interviews and records of works by participants allowed collecting conceptions for performances. The results showed consensus in conceptions of composers and styles on what the participants had already previous experience of practice of the repertoire (Haydn, Chopin), but in Bartók consensus was few. Thus, the present investigation brought evidences that the relational references of previous modes of musical expression, explicit organization of understanding (pre-conceived), as well as reception/perception as an interpreter-listener seem to be consistent indications of interconnecting stylistic knowledge and advancing perspectives of musical knowledge of instrumentalists in training.

Keywords: Musical Knowledge. Style. Musical Practice. Pianist. Performance. 


\section{Introdução}

As experiências formais do instrumentista da música de concerto ocidental, através do acúmulo de repertórios que abarcam diferentes períodos históricos, oferecem oportunidades de sistematização de normas e convenções estilísticas que consolidam seu escopo de conhecimento musical. Esses conhecimentos sobre as questões estilísticas parecem estar atrelados a três vertentes interconectadas (BARONI, 2005), a saber:

- modos de se expressar contidas em suas performances,

- modo de organizar (e comparar) as obras em estudo em termos regularidades e peculiaridades de acordo com tradições musicológicas aprendidas

- e modo de recepção como intérprete e ouvinte.

Para Baroni (2005), na vertente da expressão, o estilo encontra-se vinculado a indicações da retórica ${ }^{3}$, ou seja, relativo a modos de elocução e de discurso de uma dada linguagem. Do ponto de vista organizacional, características de um dado repertório são identificadas como distintas daquelas de outro repertório concorrente. Nessa vertente, há graças aos aportes da musicologia sistemática, regularidades e peculiaridades das estruturas das obras, de épocas e contextos históricos distintos, entretanto, para Baroni (2005), inexiste um método consolidado de análise de estilos musicais internacionalmente reconhecidos ${ }^{4}$. Do ponto de vista do modo de recepção, a manipulação daquilo que se caracteriza como estilo acaba sendo fruto da percepção de variantes e invariantes sobre o fenômeno observado. Indivíduos utilizam estratégias para armazenar informações (sobre os objetos) na memória, sendo que essa seleção baseia-se em valores adquiridos da cultura e da familiaridade. Apreciações (e julgamentos) não conseguem ser isentos de expectativas daquilo que o indivíduo reconhece como determinado es-

\footnotetext{
1 Samuel Henrique da Silva Cianbroni é técnico instrumentista (piano) pela Escola Municipal de Artes Professora Jupyra Cunha Marcondes, bacharel em piano pela Universidade Estadual de Maringá e mestre e doutor em Música (Práticas Interpretativas) pela Universidade Federal do Rio Grande do Sul com estágio de pesquisa no Laboratório de Pedagogia do Piano da Universidade de Ottawa, no Canadá. Tem experiência no ensino do piano e teoria musical. Atualmente, integra como professor substituto o quadro de docentes do curso de Licenciatura em Música da Universidade Federal de Mato Grosso do Sul.

2 Regina Antunes Teixeira dos Santos possui graduação em Música (habilitação em piano) pela Universidade Federal do Rio Grande do Sul, especialização em Interpretação pianística pelo Ueno Gakkuen (Japão), especialização em Harmonie-Analyse-Histoire de la Musique pela Conservatoire National de Region de Toulouse (França), mestrado em Education Musicale pela Université de Toulouse II - Le Mirail (França), e mestrado e doutorado em Música pela Universidade Federal do Rio Grande do Sul. Atualmente é professora adjunta da UFRGS nas disciplinas de Psicologia da Música e Teclado, além de orientar no programa de pós-graduação em Música da instituição. Tem experiência na área de Artes, com ênfase em Música, atuando principalmente nos temas: piano, conhecimento musical, repertório, formação superior, prática instrumental.

3 Desde a Antiguidade o conceito de estilo parece estar relacionado com a linguagem. O Dicionário Grove traz no termo estilo, algo que denota um modo de discurso e expressão, e mais particularmente a forma pela qual uma obra de arte é executada. No âmbito musical, o termo suscita dificuldades especiais, pois pode ser usado para denotar características musicais individuais de um compositor, de um período, de um centro ou área geográfica, ou de uma sociedade ou função social.

4 Neste sentido, Rosen (2003) abordou, por exemplo, questões da musicologia tradicional, já La Rue (1989), por sua vez, através de seu manual de análise de parâmetro por parâmetro (melodia, ritmo, harmonia, por exemplo) propôs um raro exemplo de análise estilística.
} 
tilo, desta forma, o instrumentista lida com essas três vertentes em seu conhecimento musical através de suas próprias vivências com repertórios distintos ${ }^{5}$.

Para Song e King, (2020, p. 267) a abordagem de músicos da tradição de concerto ocidental é multidimensional, talvez por eles mudarem a forma de raciocínio de acordo com as características do repertório em estudo. Instrumentistas confiam em informações primárias em relação à notação, ou no conhecimento prévio em situações de estudo formal, ou ainda adotam abordagens analíticas e intuitivas ${ }^{6}$. Assim, pode-se entender que o aprendiz em música na tradição de concerto ocidental adquire sua compreensão musical através de suas formas de fazer (musicalidade aprendida) e de escutar, o que aponta para dimensões interdependentes e mutuamente interativas de seu pensamento e conhecimento musical (ELLIOTT e SILVERMAN, 2015).

Algumas pesquisas que lidam com questões estilísticas, procuram sistematizar tendências comuns em termos organizacionais estabelecendo modelos matemáticos para evidenciar recorrências nas composições pertencentes a diferentes estilos e contextos. Por exemplo, Weiß et al. (2019) investigaram características probabilísticas na classificação de contextos tonais ambíguos em obras sinfônicas tonais dos períodos Barroco, Clássico, Romântico e Moderno. Já Bae, Park e Park (2014), através da análise do conteúdo de mídias de CDs disponíveis digitalmente, desenvolveram um algoritmo que permite a detecção de redes e comunidades profundamente relacionadas que podem estar influenciando as expectativas comuns em ouvintes, bem como influenciando a recorrência de repertórios comuns sobre períodos que vão desde a Renascença até a era Moderna. Ainda, outra modalidade investigada refere-se a formas de recepção do estudante de música como ouvinte, em que Tizón e Gomez-Martín (2020) apontaram evidências de que o reconhecimento da referência estilística por estudantes de Música em contexto universitário estiveram atreladasàsimilaridade nas projeções de respostas emocionais para obras escritas no modo maior e diferenças mais substanciais para o modo menor. Até então, ao nosso conhecimento faltam estudos na literatura de prática musical que investiguem as conexões entre questões estilísticas e conhecimento musical.

Elliott (1995) e Elliott e Silvermann (2015) compreendem conhecimento musical como algo concebido no sentido de saber fazer algo habilmente (o que denominam de musicalidade), de maneira a incluir julgamentos normativos em relações a padrões, tradições e éticas de certo domínio, e também conhecimento no sentido de compreender

\footnotetext{
5 A clássica definição de Meyer (1996) de estilo como "a reprodução de padrões ou produções no comportamento humano que resultam de uma série de escolhas feitas dentro de um conjunto de restrições" (MEYER, 1996, p. 3) está voltada para a visão de Música como linguagem e engloba aspectos, sobretudo da composição e da musicologia, bastante parecida com a segunda vertente proposta por Baroni (2005). Neste sentido, para a categorização de elementos do estilo, Meyer (1996) propõe definições aos conceitos de Leis, Regras, Estratégias, Dialeto, Idioma e Estilo Intraopus.

6 Esta visão da influência do conhecimento musical na performance é consistente com estudos anteriores, como por exemplo Swanwick (1994) e Sloboda (2000). Para Swanwick (1994, p.26-44), a consciência intuitiva ou estética é necessária, mas não uma condição suficiente para a compreensão artística. Como todo discurso simbólico, no fazer musical é necessário relacionar pensamentos intuitivos com aqueles de natureza analítica. Para Sloboda (2000, p.87-88), a construção de uma dada performance requer, no mínimo, três fases: (i) formatação de uma representação formal da estrutura musical (obtida graças à intuição e, principalmente, pela análise); (ii) atribuição de microvariações temporais de expressão que estarão retidas no dicionário expressivo do intérprete e (iii) aquisição programação motora.
} 
princípios e disponibilizá-los em situações contextualizadas ${ }^{7}$. Elliott (1995) apresenta cinco tipos de conhecimentos como constituintes da musicalidade, a saber: o conhecimento procedimental, formal, informal, impressionista e supervisor. O conhecimento procedimental suporta os outros quatro tipos de conhecimento e é essencial para o fazer musical, pois demonstra o knowhow da atividade. Conhecimento formal, por sua vez inclui ações verbais, conceitos, descrições, teorias e textos informativos sobre música. Já o conhecimento informal é um componente da musicalidade que solidifica o desenvolvimento dos esforços na prática da resolução de problemas musicais em relação aos padrões, tradições, história e conhecimento do contexto musical. 0 conhecimento impressionista também pode ser chamado de intuição e está ligado às emoções e sentimentos que por sua vez estão integrados, ou seja, são interdependentes. Finalmente, o conhecimento supervisor pode ser chamado de metaconhecimento ou metacognição, uma vez que combina senso julgamento pessoal com entendimento ético dos deveres das ações musicais.

Recentemente, Elliott e Silvermann (2015) propuseram uma ampliação para oito tipos de pensamentos e conhecimento musical em termos de duas dimensões interdependentes e mutuamente interativas: a musicalidade e a escuta. Para os autores, tanto a musicalidade como a escuta musical envolvem o conhecimento processual, verbal, experiencial, situado, intuitivo, apreciativo, ético e supervisor. Para esses autores aquele que dispõe do "saber como" fazer algo de maneira competente tem o conhecimento em termos robusto da compreensão musical de um certo contexto, e realiza em sua prática julgamentos sobre escolhas potenciais e modos de agir com detalhes específicos que incluem responsabilidades éticas e musicais aí implícitas. Em outras palavras, existem ideias, concepções e escolhas que o instrumentista faz, sendo que um dos aspectos desta compreensão musical em nível de competência refere-se às decisões ditadas pelas convenções estilísticas.

Na prática da música de concerto ocidental, pianistas em nível de pós-graduação, independentemente de ter ou não instrução formal acadêmica nesta Instituição, potencialmente são aqueles estudantes que dispõem de competência musical pelas vivências prévias contextualizadas com o estudo (e performance) de diferentes repertórios. A hipótese é que esta população seria aquela que poderia demonstrar similaridades e diferenças em termos de conhecimento de normas e convenções estilísticas. Cone (1995), trabalhando com a figura do pianista, argumenta sobre a função do intérprete como um crítico. Segundo o autor, ao abordar uma obra, o intérprete depende primeiramente da sua intuição que é guiada pela experiência, mas também é necessária uma combinação de análise sonora associada ao conhecimento musical mais formalizado. Supõe-se que ao se depararem com obras de diferentes períodos históricos, pianistas pós-graduandos demonstrem concepções e ideias contendo uma ampla gama de conhecimentos musicais em construção,

7 Numa abordagem geral, Carrascoso (1999) diz que do ponto de vista da construção pessoal de conhecimento, este deveria ser considerado "como uma atividade real que tem lugar mediante uma sucessão de atos ao longo de um tempo" (CARRASCOSO, 1999, p. 97), e por isso deve ser visto como uma realização circunstancial e ser passível de observação ao longo de um determinado tempo e em determinado contexto. 
podendo assim trazer reflexões e contribuições para os estudos que entrelaçam temáticas de conhecimento musical e concepções estilísticas.

Considerando a vastidão de conhecimentos envolvidos no fazer musical e suas naturezas, o presente artigo tem por objetivo mapear indícios de conhecimentos musicais nas concepções musicais preliminares de estilo demonstradas nas falas de jovens pianistas em nível de pós-graduação na preparação de três obras impostas de períodos históricos distintos.

\section{Metodologia}

A metodologia deste estudo consistiu em um quase-experimento em que três estudantes de piano em nível de pós-graduação (mestrado e doutorado em Práticas Interpretativas) aprenderam individualmente três obras de diferentes compositores, a saber: Haydn, Chopin e Bartók. Uma peça curta de cada um desses compositores (Tabela 1) foi escolhida para o estudo, de acordo com sua extensão (não mais que duas páginas) e nível de dificuldade (passivel de apreendida preliminarmente, em uma primeira abordagem, em sua completude em duas sessões de prática, pelos sujeitos da pesquisa). Os participantes, escolhidos por conveniência, exploraram cada uma das peças com as sessões de estudo limitadas ao tempo máximo de 30 minutos cada. Na primeira sessão, os pianistas tinham disponível a partitura e o piano para praticar, e na segunda sessão, no âmbito dos 30 minutos delimitados, contavam com a possibilidade adicional de consultar três registros comerciais retirados da plataforma YouTube®.

\section{Participantes}

Abigail ${ }^{8}$ tinha 26 anos de idade e 10 anos de estudo do piano, sendo que já havia estudado órgão anteriormente. A participante cursava o primeiro semestre do doutorado e suas experiências prévias com as obras dos compositores da pesquisa foram uma sonata de Haydn; um noturno, uma balada e um estudo de Chopin; e nenhuma experiência com a obra de Bartók.

lara estava com 25 anos, cursava também o primeiro semestre do doutorado e dispunha de 17 anos de estudo do instrumento. Suas experiências prévias com os compositores incluíam duas sonatas de Haydn; diversos gêneros em Chopin como valsa, noturno, estudo, prelúdio, fantasia, improviso e scherzo; e danças de Bartók, bem como a obra Mikrokosmos sobre a qual a participante relatou que fez parte da sua formação.

Jerônimo, por sua vez, tinha 29 anos de idade, cursava o primeiro semestre do mestrado e tinha 14 anos de estudo do instrumento. O participante já havia estudado duas sonatas de Haydn, vários gêneros de Chopin como noturnos, baladas, estudos e

8 Cada participante escolheu seu próprio pseudônimo. 
valsas; e com respeito a Bartók, leu algumas peças do Mikrokosmos quando era criança, mas relatou nunca haver tocado nada do compositor em público.

O Quadro 1 apresenta o procedimento da investigação que totalizou nove sessões de coletas (divididas em duas partes cada) gerando aproximadamente 15 horas e 30 minutos de gravação em áudio e vídeo.

\begin{tabular}{|c|c|c|}
\hline PARTICIPANTE & COMPOSITOR/PEÇA & PROCEDIMENTO \\
\hline \multirow{2}{*}{ lara/Abigail/Jerônimo } & $\begin{array}{c}\text { Haydn - Minueto e } \\
\text { trio/ } 20 \text { movimento da } \\
\text { sonata em dó maior Hob } \\
\text { XVI n. } 10\end{array}$ & $\begin{array}{l}\text { Sessão de estudo 1. Até } 30 \text { minutos de estu- } \\
\text { do (partitura + piano) } \\
\text { Gravação das performances após Sessão } 1 \\
\text { Entrevista após a gravação das performances } 1\end{array}$ \\
\hline & $\begin{array}{l}\text { Bartók - Old dance } \\
\text { tunes- n. } 7 \text { das } 15 \\
\text { canções húngaras } \\
\text { camponesas }\end{array}$ & $\begin{array}{l}\text { Sessão de estudo 2. Até } 30 \text { minutos de estu- } \\
\text { do (partitura + piano }+3 \text { gravações comer- } \\
\text { ciais disponíveis para consulta) } \\
\text { Gravação das performances após Sessão } 2 \\
\text { Entrevista após a gravação das performances } 2\end{array}$ \\
\hline
\end{tabular}

Quadro. 1: Procedimento de coleta de dados.

A ordem da coleta de dados foi estabelecida pelos princípios do quadrado latino (ELLISON, BARWICK \& FARRANT, 2009) de modo a não gerar resultados viciados, e os procedimentos de registro individuais para cada obra, foram realizadas em dias diferentes para garantir a boa participação e interesse dos sujeitos. Seguindo este princípio, um participante aprendeu na ordem Haydn-Chopin-Bartók, outro na ordem Chopin-Bartók-Haydn, e outro na ordem Bartók-Haydn-Chopin.

O roteiro das entrevistas de natureza semiestruturada, contou com quinze questões gerais, sendo que para algum esclarecimento que se fizesse necessário, questões adjacentes eram realizadas dentro do roteiro preestabelecido. O material a ser apresentado e discutido no presente artigo refere-se ao conteúdo de três questões da primeira entrevista, bem como na última questão da segunda entrevista, cujas perguntas tratavam diretamente dos compositores e suas respectivas obras e estilos, totalizando assim quatro questões. O Quadro 2 apresenta as quatro questões selecionadas: 


\begin{tabular}{|c|l|}
\hline 1 & Como você define o estilo deste compositor? \\
\hline 2 & Quais são as suas ideias em termos sonoros e estruturais sobre este estilo? \\
\hline 3 & O que você acha importante ressaltar na performance de uma obra deste estilo? \\
\hline 4 & $\begin{array}{l}\text { Se você fosse gravar esta obra (gravação comercial) o que você acha que seria mais } \\
\text { importante mostrar na sua interpretação em aspectos estilísticos para a compreensão } \\
\text { dos ouvintes? }\end{array}$ \\
\hline
\end{tabular}

Quadro 2: Questões realizadas nas entrevistas para a coleta de dados.

Essas questões serviram de arcabouço direcionador para os questionamentos a cada participante ao longo das sessões de entrevistas no quase-experimento. As entrevistas objetivaram registrar as ideias e pensamentos dos participantes, e foram delineadas como forma de extrair os conhecimentos musicais de natureza declarativa aos objetos impostos.

As entrevistas foram registradas ${ }^{9}$ em arquivo de vídeo e totalizaram cerca de 5 horas e 19 minutos. A análise de conteúdo das entrevistas ocorreu de forma indutiva, ou seja, os próprios dados começaram a fornecer indícios de aspectos mencionados/enfatizados pelos participantes sendo observados pelos termos ou conjuntos de ideias mais recorrentes nessas questões que tangenciavam diretamente o estilo do compositor.

\section{Resultados}

Os dados serão apresentados primeiramente pelas declarações verbais obtidas ao longo das entrevistas após as sessões de estudo das peças impostas. O Quadro 3 demonstra as concepções que os pianistas tinham dos estilos de Haydn, Chopin e Bartók.

9 As entrevistas também foram integralmente transcritas gerando um volume de 154 páginas. 


\begin{tabular}{|c|c|c|c|}
\hline \multicolumn{4}{|c|}{ Como você define o estilo deste compositor? } \\
\hline & Haydn & Chopin & Bartók \\
\hline lara & $\begin{array}{l}\text { Eu sinto que ele é muito } \\
\text { elegante, ele tem muita } \\
\text { clareza, [e] que às vezes ele } \\
\text { é muito humorístico. }\end{array}$ & $\begin{array}{l}\text { Tudo lembra muito canto. } \\
\text { Chopin é muito melódico, } \\
\text { muita improvisação na } \\
\text { melodia, lírico na melodia, } \\
\text { para mim é melodia. }\end{array}$ & $\begin{array}{l}\text { Eu acho que isso é muito } \\
\text { marcante no Bartók, essa } \\
\text { questão da rearmonização. } \\
\text { De ele pensar a mesma } \\
\text { melodia duas, três vezes, } \\
\text { quatro vezes, com harmonias } \\
\text { diferentes. Às vezes é no } \\
\text { mesmo modo, às vezes } \\
\text { mudando de modo. }\end{array}$ \\
\hline Abigail & $\begin{array}{l}\text { Para mim, as ideias dele } \\
\text { são muito claras, muito } \\
\text { estruturadas. Organização } \\
\text { macro e micro, claras. }\end{array}$ & $\begin{array}{l}\text { Para mim, Chopin é muito } \\
\text { melancólico, muito intenso. }\end{array}$ & $\begin{array}{l}\text { Eu acho que Bartók sempre } \\
\text { me remete a uma coisa } \\
\text { muito percussiva, e sempre } \\
\text { duro. Uma sonoridade rústica } \\
\text { e dura, pesante. }\end{array}$ \\
\hline Jerônimo & $\begin{array}{l}\text { Estilo clássico! Refinamento, } \\
\text { melodia acompanhada, } \\
\text { harmonia clássica, não tão } \\
\text { complexa, frase clara. }\end{array}$ & $\begin{array}{l}\text { O mais importante é tirar } \\
\text { esse componente lírico, o } \\
\text { canto. Sempre está o canto } \\
\text { presente. Improvisatório } \\
\text { também, isso é muito } \\
\text { importante! Essa cara de } \\
\text { improvisação. }\end{array}$ & $\begin{array}{c}\text { Folclórico, rudimentar, } \\
\text { primitivo. No sentido bom da } \\
\text { palavra primitivo. Ele gravava } \\
\text { a música das pessoas que ele } \\
\text { conhecia de diferentes povos, } \\
\text { então ele queria resgatar essa } \\
\text { música primitiva. }\end{array}$ \\
\hline
\end{tabular}

Quadro 3: Concepções dos participantes sobre as definições dos estilos dos compositores ao longo de duas práticas de estudo impostas.

Com respeito a Haydn, os participantes convergem no elemento clareza, sendo que Jerônimo salienta mais especificamente a clareza da frase. Aqui parece haver um indício de que clareza pode estar aliada à simplicidade do discurso musical com o delineamento melódico estruturado pela conhecida quadratura do Classicismo vienense. Para Harnoncourt (1988, p. 157), na transição entre os períodos Barroco e Clássico, a intenção social da música era se dirigir a todos, incluindo as massas. Neste sentido, - Classicismo coloca o elemento melódico em primeiro plano, ou seja, as melodias deveriam ser fáceis e convincentes, com o acompanhamento mais simples possível (HARNONCOURT, 1988), sendo este aspecto percebido pelos participantes no minueto estudado. Nesses depoimentos, as vertentes interconectadas de modo de recepção e de entendimento organizacional das obras parecem estar mais evidentes.

Em Chopin, é possível perceber que lara e Jerônimo enfatizaram novamente o aspecto melódico, sendo que Jerônimo também menciona a improvisação, ressaltando assim o lirismo de Chopin. Pode-se dizer que aqui Jerônimo, menciona a vertente de estilo relacionada ao modo de expressão, ressaltando este "componente lírico do can- 
to", por ele detectado. Dahlhaus (1989, p. 117) aponta que o estilo melódico de Bellini nas árias e, sobretudo, nos cantábiles lentos, é o que existe de melhor no século XIX com respeito ao que se entende do termo melodia, e que Chopin, principalmente nos noturnos, foi claramente influenciado pelo compositor italiano. É possível que Abigail tenha se referido a este lirismo ao apontar a intensidade e melancolia de Chopin, pois como afirma Copland, os compositores românticos partem da premissa de que sua música é fundamentalmente uma expressão das emoções pessoais e essa atitude subjetiva colocava toda ênfase na exibição aberta e desinibida dos próprios sentimentos (COPLAND, 1969, p. 23).

Ao abordarem o estilo de Bartók, Abigail e Jerônimo trouxeram o aspecto percussivo, muito provavelmente por terem pouco contato com a obra do compositor húngaro e estarem basicamente atentos (como ouvintes) a esta característica. Com respeito a este tipo de abordagem, Nissman (2002, p. 112) comenta que Liszt e Bartók estão envolvidos na mesma tradição, que a bravura no pianismo daquele é claramente vista neste, mesmo que o excesso do sentimentalismo romântico tenha forjado um estilo mais percussivo. lara, por sua vez trouxe a questão da rearmonização e do modalismo bartókiano, demonstrando assim conhecimento da escrita do compositor, fato que se deve provavelmente pela sua maior proximidade com a obra de Bartók.

O Quadro 4 traz as declarações dos pianistas sobre as ideias em termos sonoros e estruturais dos estilos dos compositores. 


\begin{tabular}{|c|c|c|c|}
\hline \multicolumn{4}{|c|}{ Quais são as suas ideias em termos sonoros e estruturais sobre este estilo? } \\
\hline & Haydn & Chopin & Bartók \\
\hline lara & $\begin{array}{c}\text { É um som preciso. Às vezes } \\
\text { meio perolado. Me remete } \\
\text { muito a isso, sabe? Essa } \\
\text { coisa elegante. }\end{array}$ & $\begin{array}{l}\text { Considerando que existem } \\
\text { camadas de melodias, } \\
\text { eu penso que esse tipo } \\
\text { de música tem que ser } \\
\text { pensado na condução } \\
\text { dessas melodias de } \\
\text { camadas. Para mim, seria } \\
\text { um som bastante cantábile, } \\
\text { de uma forma geral. }\end{array}$ & $\begin{array}{l}\text { Aproveitar essas mudanças } \\
\text { das rearmonizações, para } \\
\text { mudar, diversificar. Dar uma } \\
\text { cara diferente para cada } \\
\text { frase, para cada melodia que } \\
\text { se rearmoniza. Então, isso } \\
\text { tem que estar muito claro em } \\
\text { termos estruturais. }\end{array}$ \\
\hline Abigail & $\begin{array}{l}\text { É uma sonoridade límpida, } \\
\text { simples, sem muito vai e } \\
\text { volta de dinâmica, sem } \\
\text { muitas nuances. Só você } \\
\text { entender o } 3 \text { por } 4 \text { da } \\
\text { música eu acho que já vai } \\
\text { dar o caráter dela, que me } \\
\text { lembra algo camponês. }\end{array}$ & $\begin{array}{l}\text { Eu tenho a melodia aquela } \\
\text { coisa muito melosa. É muito } \\
\text { expressivo. Iniciar uma frase } \\
\text { muito delicada, fazer o } \\
\text { crescendo e terminar a frase. } \\
\text { Eu penso muito nos finais e } \\
\text { inícios de frase em Chopin. }\end{array}$ & $\begin{array}{c}\text { Atacada, rústica mesmo, eu } \\
\text { penso em rústico. As frases } \\
\text { são claras. As seções } \\
\text { são claras. }\end{array}$ \\
\hline Jerônimo & $\begin{array}{c}\text { Primeiro estruturais: } \\
\text { normalmente são frases } \\
\text { de oito compassos. O ideal } \\
\text { sonoro é clareza. Em termos } \\
\text { sonoros, tem que ficar o } \\
\text { mais claro possível, o mais } \\
\text { nítido possível. }\end{array}$ & $\begin{array}{l}\text { Em termos sonoros, } \\
\text { sempre o canto. É } \\
\text { isso, o canto, melodia } \\
\text { acompanhada. O legato, } \\
\text { por exemplo, é muito } \\
\text { importante. }\end{array}$ & $\begin{array}{l}\text { Em termos estruturais, acho } \\
\text { que corresponde muito ao } \\
\text { folclórico, muitas têm forma } \\
\text { canção. E em termos de som, } \\
\text { mais primitivo, percussivo. As } \\
\text { dinâmicas são mais estáveis. }\end{array}$ \\
\hline
\end{tabular}

Quadro 4: Concepções dos participantes sobre as ideias sonoras e estruturais dos estilos dos compositores ao longo de duas práticas de estudo impostas.

Percebe-se que ao falarem de Haydn, os participantes parecem trazer o elemento clareza como fundamental também na sonoridade. lara foca na precisão do som; Abigail tangencia a mesma ideia ao falar de um som límpido, algo que também é trazido por Jerônimo ao falar de nitidez. Deste modo, os três pianistas demonstram ideias bastante parecidas e consensuais sobre o que pensam da sonoridade haydniana.

Ao falarem sobre Chopin, os participantes convergiram para o delineamento melódico. lara ainda mencionou a estratégia contrapontística de composição usada por Chopin ao falar das camadas melódicas, Abigail descreve sobre a forma de frasear com a ideia do contorno melódico e direcionamento das linhas (CLARKE, 1989), e Jerônimo, por sua vez, volta ao seu pensamento inicial mencionando a comparação com a voz cantada e como conseguir este efeito no piano através da articulação.

Quando comentaram sobre Bartók, as diferenças foram mais perceptíveis. Tanto Abigail quanto Jerônimo focaram na dinâmica forte presente na obra do compositor, 
o que Jerônimo remete ao folclore explorado por Bartók. Para Copland (1969, p. 66), a música de Bartók é de uma elaboração seca e pouco sentimental, repleta de ritmos incisivos e dissonâncias agudas harmônicas. lara, por sua vez focou nas estratégias composicionais (MEYER. 1996) do compositor, valorizando as mudanças de harmonização que ela mesma mencionou na resposta anterior.

O Quadro 5 traz as declarações dos pianistas sobre o que achavam importante ressaltar em uma obra dos estilos que estudaram.

\begin{tabular}{|c|c|c|c|}
\hline \multicolumn{4}{|c|}{ O que você acha importante ressaltar na performance de uma obra deste estilo? } \\
\hline & Haydn & Chopin & Bartók \\
\hline lara & $\begin{array}{c}\text { Como que se organiza e } \\
\text { como se delineiam as frases. } \\
\text { O contorno melódico. Essa } \\
\text { coisa da frase, da estrutura, } \\
\text { das cadências e essa coisa } \\
\text { do timbre nos contrastes } \\
\text { que é o que eu acho que dá } \\
\text { a dramaticidade. }\end{array}$ & $\begin{array}{c}\text { Acho importante ressaltar } \\
\text { essa coisa das camadas. } \\
\text { Muita tensão e resolução, } \\
\text { isso é muito importante, } \\
\text { tanto no nível de progressão } \\
\text { harmônica quanto no nível } \\
\text { de ornamentação melódica. } \\
\text { A variação agógica, que eu } \\
\text { acho muito característica, } \\
\text { também. }\end{array}$ & $\begin{array}{l}\text { O que mudou, de que } \\
\text { maneira mudou, como é } \\
\text { que eu posso mostrar essas } \\
\text { mudanças dessa repetição } \\
\text { do material, tanto nessa } \\
\text { questão da textura, da } \\
\text { articulação, da dinâmica } \\
\text { também, mas especialmente } \\
\text { da rearmonização, que muda } \\
\text { o caráter total da melodia. }\end{array}$ \\
\hline Abigail & $\begin{array}{l}\text { Aqui no caso minueto e } \\
\text { trio são danças. Então, é } \\
\text { importante o intérprete ter } \\
\text { a métrica, não fugir dela, } \\
\text { não só dentro do compasso } \\
\text { quanto à métrica da frase. } \\
\text { Acho que as ornamentações } \\
\text { são importantes, que é do } \\
\text { estilo Clássico. }\end{array}$ & $\begin{array}{c}\text { Eu acho que é importante } \\
\text { ressaltar sempre que é um } \\
\text { três por quatro, os primeiros } \\
\text { tempos e a melodia. Uma } \\
\text { coisa que estilisticamente é de } \\
\text { Chopin, essa coisa da agógica } \\
\text { de ser muito expressivo em } \\
\text { relação à agógica. }\end{array}$ & $\begin{array}{c}\text { Como é tudo muito forte e } \\
\text { pesante, eu pensei muito na } \\
\text { questão do tempo forte do } \\
\text { compasso. Tomar cuidado } \\
\text { com a sonoridade. E ritmo em } \\
\text { Bartók, para mim eu acho que } \\
\text { é fundamental. Sonoridade, } \\
\text { ritmo e métrica! }\end{array}$ \\
\hline Jerônimo & $\begin{array}{l}\text { A clareza! Por exemplo, } \\
\text { tendo a clareza da frase } \\
\text { musical. Quando é } \\
\text { melodia acompanhada, } \\
\text { claramente a melodia e o } \\
\text { acompanhamento claro, } \\
\text { quando é polifônico, que se } \\
\text { escute a polifonia } \\
\text { bem definida. }\end{array}$ & $\begin{array}{l}\text { Me veio na cabeça a } \\
\text { flexibilidade. Não tem que } \\
\text { ter flexibilidade porque } \\
\text { sim, mas pelo canto. Se } \\
\text { preciso de mais tempo } \\
\text { para alcançar um intervalo, } \\
\text { preciso fazer rubato. Soar } \\
\text { livre, flexível, não pode soar } \\
\text { com travas. }\end{array}$ & $\begin{array}{l}\text { É importante conhecer a } \\
\text { música folclórica húngara. } \\
\text { Conhecer como essa música } \\
\text { se expressa vocalmente, } \\
\text { percussivamente, como é } \\
\text { a música em conjunto. E } \\
\text { buscar um tratamento mais } \\
\text { percussivo do piano. Que eles } \\
\text { sintam isso, que é uma música } \\
\text { folclórica e rítmica. }\end{array}$ \\
\hline
\end{tabular}

Quadro 5: Concepções dos participantes sobre o que achavam importante ressaltar em uma obra do estilo dos compositores estudados ao longo de duas práticas impostas.

10 A participante trocou o termo "agógica" pelo termo "inflexão de timing" após a revisão de sua entrevista. 
Nesta questão, ao comentarem sobre aspectos a serem ressaltados em uma obra de Haydn, os participantes pareceram ter ideias parecidas com alguns enfoques levemente diferentes. De uma forma geral, todos se preocuparam com o delineamento das frases, sendo que lara ressaltou os contrastes; Abigail, a métrica e Jerônimo, as texturas.

Em Chopin, os pianistas trouxeram dois aspectos: melodia e agógica. lara ainda mencionou a questão da textura das camadas melódicas às quais já havia se referido anteriormente. A questão do rubato (que aqui tangencia a agógica) em Chopin é ponto de atenção na literatura. Para Rosen, (2003), por exemplo, a prática dos séculos XVIII e XIX chamada de rubato, consistia numa expressiva forma de ornamentação em que a nota da linha melódica era atrasada e tocada após a linha do baixo; já Ritterman (1992, p. 20) menciona sobre o estilo brilhante, que consistia num rápido embelezamento e elaboração da linha melódica com um baixo comedido no acompanhamento.

Ao falarem sobre os aspectos a serem ressaltados em uma obra de Bartók, lara mencionou novamente os contrastes ressaltando a escrita do compositor. Abigail e Jerônimo focaram mais na questão rítmica e sonora, sendo que este último trouxe a questão folclórica que permeia a obra do compositor húngaro. Para Copland (1969, p. 65), Bartók foi o melhor dos folcloristas, lançando mão do material nativo como base para uma música que é de alta qualidade e muito característica da escola musical Moderna.

Por fim, o Quadro 6 apresenta as declarações dos participantes para a última questão da entrevista, que se relacionava com a projeção do que privilegiariam se, por acaso, tivessem que fazer um registro comercial das referidas obras em estudo. 


\begin{tabular}{|c|c|c|c|}
\hline \multicolumn{4}{|c|}{$\begin{array}{l}\text { Se você fosse gravar esta obra (gravação comercial) o que você acha que seria mais importante } \\
\text { mostrar na sua interpretação em aspectos estilísticos para a compreensão dos ouvintes? }\end{array}$} \\
\hline & Haydn & Chopin & Bartók \\
\hline lara & $\begin{array}{l}\text { Conseguir aliar esse estilo } \\
\text { minueto, essa estrutura } \\
\text { dança, ternária, com } \\
\text { características próprias. } \\
\text { Conseguir mostrar isso, } \\
\text { o caráter de cada parte, o } \\
\text { som de cada parte, essa } \\
\text { variação de agógica, em } \\
\text { determinados lugares, o } \\
\text { tempo de cada parte. }\end{array}$ & $\begin{array}{l}\text { Acho que esse caráter de } \\
\text { dança. Essa condução. } \\
\text { Esse voicing. O contraste } \\
\text { de seções, o contraste } \\
\text { de sonoridade entre as } \\
\text { seções, de caráter entre as } \\
\text { seções. Mas especialmente } \\
\text { essa variação do tempo. O } \\
\text { tempo para modelar cada } \\
\text { frase, modelar cada seção. }\end{array}$ & $\begin{array}{l}\text { Eu acho bastante importante } \\
\text { mostrar isso do contraste } \\
\text { das seções, contraste } \\
\text { de qualidade de som, as } \\
\text { diferenças sonoras de uma } \\
\text { forma geral assim: timbre, } \\
\text { dinâmica, articulação. Eu } \\
\text { vejo muito relacionado } \\
\text { à textura. }\end{array}$ \\
\hline Abigail & $\begin{array}{l}\text { A clareza das ideias musicais, } \\
\text { não ficar rebuscando muito, } \\
\text { não ficar inventando coisa } \\
\text { em questão de nuances } \\
\text { de dinâmica e agógica. Eu } \\
\text { acho que seguir a métrica, } \\
\text { os ornamentos, já deixa a } \\
\text { música bonita, e já deixa no } \\
\text { estilo que ela tem que ser. }\end{array}$ & $\begin{array}{l}\text { Na seção A, eu me concentraria } \\
\text { mais na melodia porque é } \\
\text { simples o acompanhamento } \\
\text { da mão esquerda, aqui. Eu } \\
\text { acho que na seção B, o que } \\
\text { estilisticamente deixaria o } \\
\text { caráter mais up seria a junção da } \\
\text { escrita da mão esquerda coma } \\
\text { sensibilidade do pianista de sua } \\
\text { utilização do pedal. }\end{array}$ & $\begin{array}{c}\text { Acho que a questão da } \\
\text { dança pesante. Veio isso na } \\
\text { mente, porque ela não é uma } \\
\text { dancinha delicadinha, é uma } \\
\text { dança robusta. }\end{array}$ \\
\hline Jerônimo & $\begin{array}{l}\text { Clareza. E limpo, sem } \\
\text { reverberação excessiva. Sem } \\
\text { que o pedal ligue as notas } \\
\text { que não têm porque serem } \\
\text { ligadas. O trabalho musical } \\
\text { é feito pelas articulações, o } \\
\text { arco de frase, a dinâmica. E } \\
\text { essa coisa orquestral e de } \\
\text { câmara, que se note que é } \\
\text { um quarteto, um trio. }\end{array}$ & $\begin{array}{l}\text { O caráter rítmico que tem a } \\
\text { mazurca. Isso do apoio no } \\
\text { segundo tempo. E na seção } \\
\text { do canto que seja cantado. }\end{array}$ & $\begin{array}{l}\text { É isso. Folclórico. Essa foi a } \\
\text { palavra-chave: folclórico. } \\
\text { São pessoas que não sabem } \\
\text { escrever música, não estão } \\
\text { pensando em dois por } \\
\text { quatro, ou quatro por quatro, } \\
\text { mi bemol, si bemol. Estão } \\
\text { cantando, fazendo música. }\end{array}$ \\
\hline
\end{tabular}

Quadro 6: Concepções dos participantes sobre como gravariam comercialmente as obras que estudaram ao longo de duas práticas impostas.

Ao comentar sobre o minueto e trio de Haydn, lara se concentrou no contraste entre as sessões e ideais musicais, já Abigail e Jerônimo tangenciaram novamente a clareza que ao que indica, diz respeito às linhas melódicas claramente delineadas e sem grandes ressonâncias, bem como a definição clara do tempo e da métrica.

Na mazurca de Chopin foi possível observar diferentes enfoques: lara mais uma vez trouxe o contraste entre as seções se valendo da agógica ou o que ela mesma denominou de variação do tempo. Abigail também pensou no caráter de cada seção com respeito à escrita, mencionando sobre o acompanhamento e a utilização do pedal. Je- 
rônimo, por sua vez, mencionou novamente o aspecto vocal e também o aspecto métrico de acentuação do gênero mazurca.

Com respeito à dança de Bartók, mais uma vez lara tangenciou o contraste entre as seções, justificando pelas mudanças de textura que o compositor utiliza na obra. Abigail trouxe o caráter pesante, que ao que parece está ligado à dinâmica que ela mencionou anteriormente. Jerônimo por sua vez também falou do caráter, que ele entendeu como folclórico, fazendo alusão a um grupo de pessoas cantando. Neste sentido apontado por Jerônimo, László (2004) diz que Bartók coletou música folclórica de lugares onde praticamente não havia folcloristas antes dele, sendo assim, as melodias que descobriu são únicas. Esses materiais folclóricos foram absorvidos em sua linguagem musical individual e tornaram parte da linguagem musical do século XX (LÁSZLÓ, 2004, p. 47).

A seguir será apresentada a discussão dos dados obtidos através das respostas dos participantes, bem como uma análise deste conteúdo.

\section{Análise e Reflexões}

Ao levar em conta as respectivas concepções preliminares em formas multidimensionais de abordar o conhecimento musical pela musicalidade e escuta (ELLIOTT; SILVERMANN, 2015) nas situações de quase-experimento, aqui relatadas, foi possível perceber as diferenças e semelhanças nas falas dos participantes e como os mesmos manifestaram seus conhecimentos verbais, certamente subsidiados pelos outros conhecimentos que possuíam (ELLIOTT, 1995; SWANWICK,1994).

Ao falarem sobre a obra de Haydn e do estilo Clássico, os pianistas trouxeram o elemento clareza como algo mais preponderante. Suas concepções sugerem que o conceito de clareza está associado a diversos elementos musicais, tais como delineamento das frases, reverberação ou ressonância (relacionadas ao uso do pedal), e estrutura das sessões e texturas, por exemplo. Está presente no discurso dos participantes uma busca por refinamento e projeção sonora dos elementos musicais. Neste caso, mesmo com expressões distintas, suas declarações foram bastante consensuais, o que sugere bastante familiaridade com o estilo do compositor.

Em Chopin, o consenso também foi bastante evidente, porém com um foco maior em dois elementos: melodia e agógica (ou inflexão de timing como posteriormente foi alterado por Abigail, mas que aqui, tem o sentido semelhante à variação de tempo). Todos os participantes mencionaram estes elementos como algo fundamental na obra de Chopin, sendo que o fraseado ou, mais precisamente, a construção das melodias é indissociável da condução temporal. Aqui, mais uma vez percebe-se que existe familiaridade dos participantes tanto com o estilo, quanto com a obra de Chopin, fato que se evidencia pelas experiências prévias que possuíam, pois Chopin foi o compositor mais estudado segundo os próprios relatos dos pianistas.

Já em Bártók, os participantes demonstraram pouco consenso, com exceção da atenção que Abigail e Jerônimo evidenciaram de forma mais latente com a questão da dinâmica e do caráter percussivo do piano. Abigail, de fato, focou no aspecto dinâmi- 
co, em especial do forte. Jerônimo se deteve no caráter folclórico da peça, enquanto que lara deu atenção para as variações que Bartók faz com o material. Neste sentido, percebe-se que a experiência prévia fez diferença nos conhecimentos verbais trazidos pelos participantes, pois lara foi a única que estudou mais a fundo a obra de Bartók, e de fato conseguiu demonstrar aspectos da escrita bastante característicos do compositor, como o reaproveitamento de melodias em diferentes modos, por exemplo. Por sua vez, Abigail e Jerônimo focaram naquilo que provavelmente somente vivenciaram através de escutas das interpretações das obras do compositor, pois segundo seus relatos não tiveram experiência substancial no estudo das obras de Bartók.

Considerando os aspectos explícitos e implícitos, os pianistas demonstraram maior cuidado com a estruturação das melodias (explícito) e como as mesmas deviam ser executadas (implícito). Há uma aparente preocupação com a construção e delineamento das frases como unidades melódicas que dão ou não harmonicamente a ideia de conclusão (DODSON, 2011, p. 15). Neste sentido, lara demonstrou este foco também na obra de Bartók, algo que não foi diretamente mencionado por Abigail e Jerônimo. Ao que tudo indica, delineamento melódico parece ser o foco principal dos participantes desta pesquisa, sendo que outros fatores musicais orbitam em torno deste elemento, como por exemplo, a construção do caráter, seja ele elegante, melancólico, ou primitivo, entre outros.

Com respeito aos respectivos perfis como instrumentistas, há indícios revelados pelos depoimentos e escolhas. Nota-se que Abigail de certa forma pareceu ser um pouco mais intuitiva, declarando de acordo com aquilo que sentia ou pensava no momento, demonstrando inclusive certa dificuldade de se expressar verbalmente como se vê na primeira questão sobre a definição dos estilos dos compositores. Seu conhecimento verbal se demonstrou bastante ligado ao conhecimento procedimental e isto pode ser constatado na forma como ela descrevia a ação de tocar e os meios para se chegar musicalmente àquilo que pensava, como quando, por exemplo, descreveu o fraseado em Chopin ou a construção das gradações de dinâmica em Bartók, o que a coloca como uma instrumentista predominantemente prática.

lara demonstrou um perfil analítico frente aos diversos estilos e compositores impostos na investigação, ressaltando os aspectos característicos das respectivas escritas composicionais, e demonstrando evidente capacidade de organizar e expressar as ideias, como quando mencionou sobre as texturas e rearmonizações, por exemplo. Tal postura pode também ser vista na maneira como ela frequentemente ressaltava as nuances de contrastes e variações e como esses aspectos eram importantes na performance, o que faz inferir que a busca por estes contrastes se constitua como seu modus operandi enquanto instrumentista.

Jerônimo, por sua vez, demonstrou um perfil mais criativo através de suas imagens e das relações que idealizou, nas quais nuances de timbre e sonoridade encontravam-se ali reveladas. Para Haydn, a comparação foi com quarteto de cordas, para Chopin com voz solo e para Bartók com um grupo de pessoas cantando. As referências criadas pareceram norteá-lo para verbalizar o que queria comunicar, ajudando a suprir inclusive a falta de experiência que tinha com a obra de Bartók. Ainda assim, o participante pareceu 
equilibrar conhecimento formal e impressionista (ELLIOTT, 1995), ainda que pendendo para um lado mais estético como quando fala de lirismo e folclore. Neste sentido, imaginação e criatividade parecem ser a base predominante de sua atuação como pianista.

O Quadro 7 traz de forma mais concisa e elucidativa as características percebidas de maneira mais evidente nos participantes:

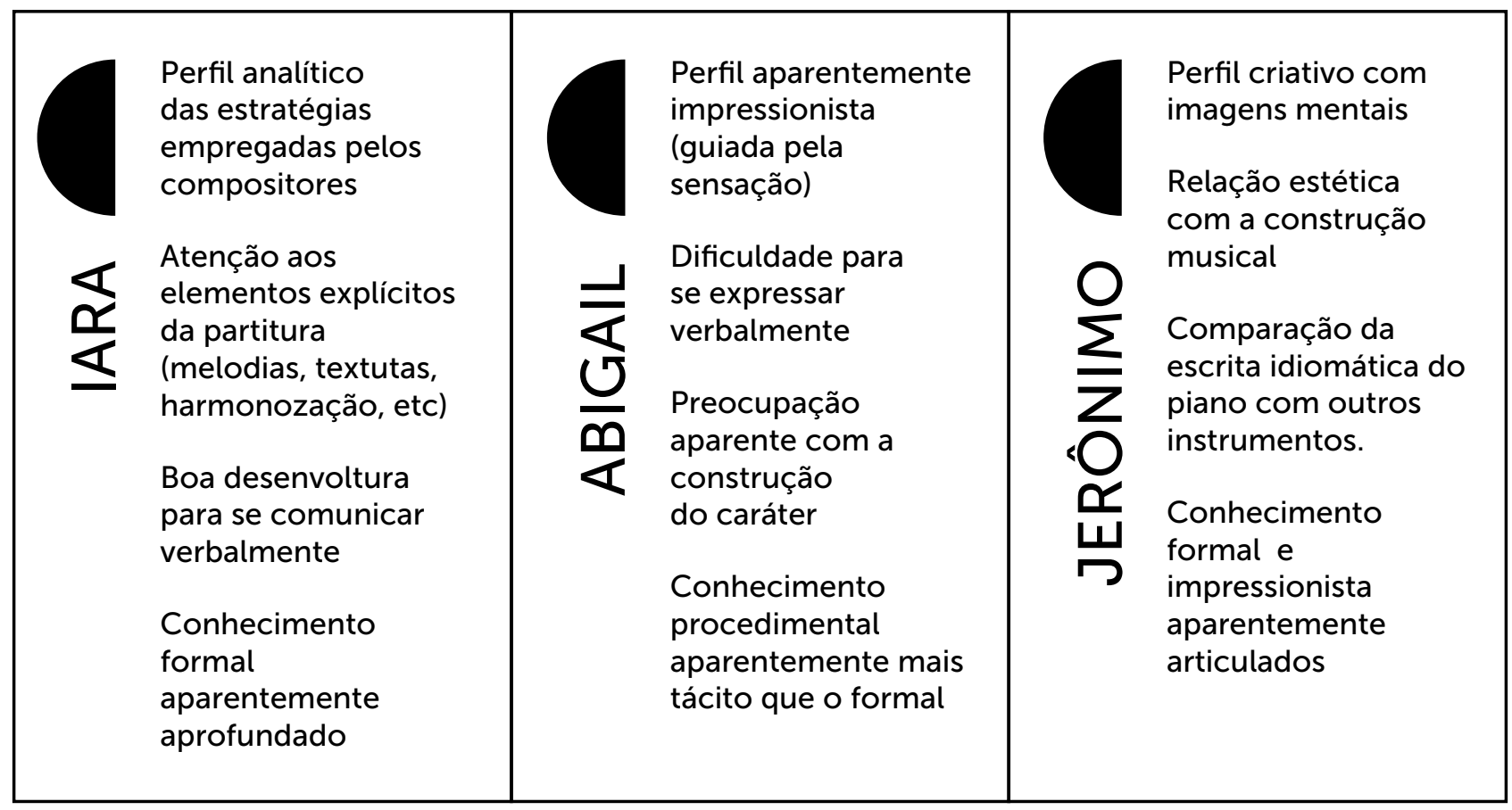

Fig. 1: Características dos perfis dos participantes de acordo com suas respostas nas entrevistas

Sendo assim, foi possível perceber os diferentes perfis dos participantes através de suas falas e como o conhecimento verbal (e formal) pode fornecer projeções de como possivelmente atuam como pianistas. Neste sentido é necessário deixar claro que são apenas projeções, pois os diferentes tipos de conhecimento podem não estar num mesmo nível (ELLIOTT, 1995), assim como atividades musicais podem ter diferentes níveis de desenvolvimento (SWANWICK, 2003).

\section{Considerações finais}

O presente artigo discutiu como três pianistas em nível de pós-graduação são capazes de expressar verbalmente suas respectivas concepções preliminares, revelando, assim, seu conhecimento formal acumulado. Nesses casos estudados, percebeu-se formas similares e distintas de expressar o conhecimento musical, o que sugere tanto - compartilhamento de concepções musicais da comunidade de prática (ao menos nesta amostra) quanto da singularidade de cada músico (MONTEIRO, 2019, p. 183). 
Neste sentido é possível fazer um paralelo com o conhecimento formal aqui apresentado, pois os pianistas entrevistados trouxeram aspectos bastante consensuais, principalmente nas obras de Haydn e Chopin, demonstrando assim o compartilhamento das ideias musicais da comunidade de prática da música de concerto pianística, bem como demonstraram suas singularidades através dos seus diferentes perfis e focos de atenção.

Ao longo desta investigação foi possivel constatar também que as experiências prévias com a obra de determinado compositor ajudaram a consolidar suas concepções durante as situações de prática, pois isso ficou evidente na forma como uma participante (lara) conseguiu explorar os aspectos explícitos da dança de Bartók, algo que os outros dois outros participantes fizeram de forma menos evidente. Esse resultado é consonante com os argumentos trazidos por Elliott e Silvermann (2015), ou seja, apontando que o "saber como" prévio e contextualizado de cada participante possibilitou referências mais específicas a serem ressaltadas para o estilo imposto em questão.

A presente investigação favorece a reflexão para além dos resultados de consensos e divergências na produção musical de um dado período histórico, pois traz evidências empíricas das relações entre concepções estilísticas e conhecimentos musicais. Assim, por meio de seus modos de expressão musical, os instrumentistas recuperaram aspectos das performances advindas de suas práticas. A verbalização sobre as obras em estudo parece ter-lhes trazido conscientização de regularidades e peculiaridades de tradições musicológicas já vivenciadas. Finalmente, sua recepção como intérpretes-ouvintes ajudou-os nas concepções sobre como tocar e o que escutar numa dada obra. Assim, a presente investigação trouxe evidências de que as referências interconectadas de modos de expressão musical prévios, organização explícita do entendimento (pré-concebido) assim como recepção como intérprete-ouvinte parecem ser indícios consistentes de interconectar conhecimentos estilísticos e avançar perspectivas de conhecimento musical de instrumentistas em formação.

\section{Referências}

BAE, A; PARK, D; PARK, J. The network of western classical musicians. 2014 Studies in Computational Intelligence 549, pp. 13-24.

BARONI, M. Style et mutations stylistiques dans la tradition musicale européenne. In: J. J. Nattiez (Org.) Musiques. Une encyclopédie pour le XXI e siècle. V. 4 - Histoires des musiques européenes. Paris: Actes de Sud (pp. 53-70), 2005.

BARTÓK, Bela. Fifteen Hungarian Peasant Songs: Old Dance Tunes n. 7. Vienna: Universal Edition, 1920, p.60.

CARRASCOSO, J.L.A. Teoría del conocimiento. Madrid: Síntesis, 1999. 
CHOPIN, Frédéric. Mazurken: Op. 33 n. 3. G. Henle Verlag, 1975. Pp. 64, 65.

CLARKE, Eric F. Generative principles in music performance. In: SLOBODA, J. A. (Ed.) Generative processes in music: The psychology of performance, improvisation, and composition. Oxford: Clarendon, p. 1-26, 1989.

CONE, Edward T. The pianist as critic. The practice of performance: Studies in music interpretation. Edited by John Rink. Cambridge University Press, 1995. Pp. 241-253.

COPLAND, Aaron. A Nova Música. Tradução: Lívio Dantas. Gráfica Record Editora. Rio de Janeiro, 1969.

DAHLHAUS, Carl. Nineteenth-Century Music. English translation by J, Bradford Robinson. University of California Press, 1989.

DODSON, Alan. Expressive timing in expanded phrases: an empirical study of recordings of three Chopin preludes. Royal Northern College of Music Vol. 4 2-29, 2011.

ELLIOTT, David J. Music Matters. Oxford University Press. New York, 1995.

ELLIOTT, David; SILVERMAN, Marissa. Music Matters: A Philosophy of Music Education. (2nd Ed). New York: Oxford University Press, 2015.

ELLISON, S.; BARWICK, V.; FARRANT, T. Designing Effective Experiments. In: Practical Statistics for the analytical Scientist: A Bench Guide. 2 ed. LGC Limited, 2009. Cap. 8, p. 131-133.

GROVE MUSIC ONLINE. Oxford Music Online. Disponível em http://www.oxfordmusiconline.com/. Acesso em 08/10/2018.

HARNONCOURT, Nikolaus. O Discurso dos Sons. Caminhos para uma nova compreensão musical. Tradução: Marcelo Fagerlande. Jorge Zahar Editor. Rio de Janeiro, 1988.

HAYDN, Joseph. Complete Piano Sonatas, Volume I: Sonata Hob XVI n. 10, mov2. G. Henle Verlag, 1970, p. 86.

LÁSZLÓ, Ferenc. Béla Bartók and the Ideal of Europe - Lecture held at the Hungarian Institute in Bucharest on May the 3rd 2004 - Copyright of Central University Library "Lucian Blaga" in Cluj-Napoca. Pp. 46-51. 
LARUE, Jan. Análisis del Estilo Musical. Pautas sobre la contribuición a la música del sonido, la armonía, el ritmo y el crecimiento formal. Editorial Labor S.A. Barcelona, 1989.

MEYER, Leonard B. Style and Music. Theory, History and Ideology. Originally published 1989 by the University of Pennsylvania Press in the series Studies in the Criticism and Theory of Music. The University of Chicago Press, 1996.

MONTEIRO, Heidi. Perspectivas de pianistas sobre expressividade em performance musical como intérpretes e ouvintes. Tese de Doutorado. Universidade Federal do Rio Grande do Sul. Instituto de Artes. Programa de Pós-Graduação em Música.

Porto Alegre, 2019.

NISSMAN, Barbara. Bartók and the Piano. A Performer's View. The Scarecrow Press, Inc. Lanham, Maryland, and Oxford 2002.

RITTERMAN, Janet. Piano music and the public concert 1800-1850. In The Cambridge Companion to Chopin. Edited by Jim Samsom. Cambridge University Press, 1992.

ROSEN, Charles. El Estilo Clásico. Haydn, Mozart, Beethoven. Versión española de Elena Giménez Moreno. Revisión de José María Martín Triana. Alianza Editorial, Madrid, 2003.

SONG, Moo Kyoung; KIM, You Jim. Speaking of your own repertoire: an investigation of music performance during practice. British Journal of Music Education (2020), 37, 260-269. Cambridge University Press.

SLOBODA, John Anthony. The music mind: the cognitive psychology of music. Oxford: Oxford University Press, 2000.

SWANWICK, Keith. Musical knowledge: intuition, and music education. London: Routledge, 1994. Ensinando Música Musicalmente. Tradução de Alda Oliveira e

Cristina Tourinho. São Paulo. Moderna, 2003.

TIZÓN, Manuel; GÓMEZ-MARTÍN, Francisco. La influencia del estilo musical em la emoción percibida. Revista Electrónica Complutense de Investigación en Educación Musical. 17, 2020: 85-108.

WEIß, Christof; MAUCH Matthias; DIXON Simon; MÜLLER Meinard. Investigating Style Evolution of Western Classical Music: A Computational Approach. Musicae Scientiae 23, no. 4 (December 2019): 486-507. 